\title{
Effectiveness of Self-Enhancement Programme on Self-Esteem among Adolescents Residing at Selected Orphanages
}

\author{
Bhuvaneshwari, Valarmathi V*, R Vijayalakshmi and C kanniammal \\ College of nursing, SRM Institute of science \&Technology, India \\ Received: 制 May 28, 2018; Published: 制 June 08, 2018 \\ *Corresponding author: Valarmathi V, College of nursing, SRM Institute of science \&Technology, Tamil Nadu, India
}

\begin{abstract}
Self-esteem is a cornerstone of positive attitude towards living. Individuals residing at orphanage homes have more needs to lead a healthy life. The development of a strong sense of self-esteem during adolescent period is important to withstand the stresses, social pressures and temptations of deviance encountered at early ages of life. The aim of this study is to determine the effectiveness of self-enhancement programme (SEP) on self-esteem among adolescents residing at selected orphanages. Quasi experimental pretest post-test control group design was used. The study was conducted at Sivananda Saraswathi Sevashram (study group) and SOS children's village (control group), Kancheepuram District. The investigator screened 200 orphan adolescents using purposive sampling technique out of which 93 had inadequate and moderate self esteem, 48 in study group and 45 in control group. The adolescents were divided into four groups to provide 5 sessions of interventions, for 4 weeks. Before and after the intervention (self-enhancement programme) of study and control group data were analysed by using spss package. The findings revealed that self-enhancement programme is effective in increasing self-esteem $(\mathrm{t}=14.37$, with $\mathrm{p}<0.01$ and hence the study concluded that SEP is effective method for enhancing self-esteem in adolescents. It recommended that periodical conduction of self-enhancement programme in schools in order to improve the self esteem of orphan adolescents.
\end{abstract}

Keywords: Effectiveness; Self-Enhancement Programme; Self-Esteem; Orphan Adolescents

\section{Introduction}

Self-esteem is the degree to which one values oneself. The level of our self esteem determines how we operate in life-how we interact with the society. It determines our goal and what we strive for, our achievements and our happiness and satisfaction in life. Healthy self-esteem is related with creativity, rationality, flexibility, willingness to admit mistakes, openness, honesty, acceptance, cooperativeness and independence. Therefore self-esteem is considered an important component of human life. Adolescence is an especially important developmental period for the formation of self-esteem. From an early age children are strongly influenced by those caring for them and if those people were overly critical and judgmental it is easy to see how this could cause one to feel inferior, rejected and worthless. So orphan adolescents have more needs to lead a healthy life.

Self-esteem refers to the degree of regard or respect that individuals have for them and is a measure of worth that they place on their abilities and judgments. Baron and Byrne explained Selfesteem as a Self-evaluation reflecting a person's overall appraisal of one's own worth. It is one's attitude towards oneself along a positive-negative dimension resulting in either high or low selfesteem. (Mary C Townsend)[1] Adolescences who are orphans are one of most vulnerable, helpless and needy group of adolescence. This adolescents are suffering from inadequate self-esteem. As the population of orphan children is growing in epidemic proportions, there is an enormous immediate need to give the necessary care for those orphans so that they have a fruitful life and a bright future. The aim of this study to assess the effectiveness of self enhancement program on self- esteem among adolescents residing in orphanages. An individual who is exposed to self enhancement programme may be better equipped to face decisions and to make better life choices. If they can learn to value themselves, then they are able to value others around them and also feel good about the world in which they live. Self enhancement programme plays 
a vital role in enhancing self-esteem of an individual. Hence, self enhancement activities can be taught as a means to boost up the self-esteem of an individual. Earlier the intervention, better the outcome, hence adolescence is the most appropriate period to instill self enhancement programme in an individual.

\section{Background of the Study}

The self-esteem, however, is something more fundamental than the normal ups and down associated with situational changes. In contrast, for people with poor self-esteem, these ups and downs drastically impact the way they see themselves. The global population of adolescents is 1.2 billion who stands at crossroads between childhood and the adult world. It is estimated that there are 140 million orphans worldwide (UN World Health Report (2012), suicide is the third leading cause of death among adolescents. Low self-esteem is attributed as a major risk factor for suicide ICEF, 2016) [2].

The report by Substance Abuse and Mental Health Services administration (SAMHSA), USA, (2013) shows that an annual average of 1 million orphan adolescents aged 12 to 17 years experienced a major depressive episode in the past year [3].India has the largest population of adolescents in the world being home to 143 million individuals aged 10-19 years and it is estimated that there are 30 million orphans in India $[3,4]$.

The Lancet (2012) indicates that orphan teens in southern India have the highest suicide rate. The suicide rate in the 15-19 age groups living around Vellore in Tamil Nadu, India was 348 per 100,000 for women and 298 per 100,000 for men. Suicidal deaths accounted for between 50 to $75 \%$ of all deaths in young men and women in 15 to 19 age group [5,6]. Firdevs and Zeynep (2012) conducted a study to explore the relationship between self-esteem, perceived social support and helplessness in orphan adolescents. A total of 257 orphan adolescents, the findings indicated that a casual relationship was between adolescent self-esteem, perceived social support and hopelessness [7].

\section{Self Enhancement Program (SEP)}

\section{Findings of the Study}

Table 1: Frequency and percentage distribution of demographic variables related to self-esteem among adolescents residing at selected orphanages.

\begin{tabular}{|c|c|c|c|c|c|}
\hline \multirow{2}{*}{\multicolumn{2}{|c|}{ Demographic variables }} & \multicolumn{2}{|c|}{ Study group $(\mathrm{N}=48)$} & \multicolumn{2}{|c|}{ Control group $(\mathrm{N}=45)$} \\
\hline & & \multirow{2}{*}{$\begin{array}{c}\mathbf{N} \\
31 \\
\end{array}$} & \multirow{2}{*}{$\begin{array}{c}\% \\
64.6\end{array}$} & \multirow{2}{*}{$\begin{array}{c}\mathbf{N} \\
25 \\
\end{array}$} & \multirow{2}{*}{$\begin{array}{c}\% \\
55.6 \\
\end{array}$} \\
\hline A & $13-15$ years & & & & \\
\hline Hec & $16-18$ years & 17 & 35.4 & 20 & 44.4 \\
\hline \multirow{2}{*}{ Gender } & male & 27 & 56.3 & 22 & 48.9 \\
\hline & female & 21 & 43.8 & 23 & 51.1 \\
\hline \multirow{3}{*}{ Education } & $8^{\text {th }}$ & 14 & 29.2 & 11 & 24.4 \\
\hline & $9^{\text {th }}$ & 10 & 20.8 & 8 & 17.8 \\
\hline & $10^{\text {th }}$ & 7 & 14.6 & 6 & 13.3 \\
\hline
\end{tabular}




\begin{tabular}{|c|c|c|c|c|c|}
\hline & $11^{\text {th }}$ & 8 & 16.7 & 11 & 24.4 \\
\hline & $12^{\text {th }}$ & 9 & 18.8 & 9 & 20.0 \\
\hline \multirow{4}{*}{ Duration of stay } & $<3$ years & 21 & 43.8 & 24 & 53.3 \\
\hline & 4-6years & 23 & 45.8 & 19 & 42.2 \\
\hline & 7-9years & 5 & 10.4 & 2 & 4.4 \\
\hline & 10years and above & 0 & 0.0 & 0 & 0.0 \\
\hline \multirow[t]{2}{*}{ Reason for admission } & $\begin{array}{l}\text { Both parent are not } \\
\text { alive }\end{array}$ & 48 & 100.0 & 45 & 100.0 \\
\hline & Illicit child & 0 & 0.0 & 0 & 0.0 \\
\hline
\end{tabular}

Table 2: Assessment of pre-test level of self-esteem among adolescents in study and in control group n=93.

\begin{tabular}{|c|c|c|c|c|}
\hline \multirow{2}{*}{ Level of self-esteem } & \multicolumn{2}{|c|}{ Study group (n2=48) } & \multicolumn{2}{c|}{ Control group (n1=45) } \\
\cline { 2 - 5 } & $\mathbf{f}$ & $\mathbf{\%}$ & $\mathbf{f}$ & 28.9 \\
\hline Inadequate self esteem & 13 & 27.1 & 32 & 71.1 \\
\hline Moderately adequate self-esteem & 35 & 72.9 & 0 & 0 \\
\hline Adequate self-esteem & 0 & 0 & & \\
\hline
\end{tabular}

Analysis revealed that in pre-test, in the study group 13(27.1\%) of the adolescents had inadequate self-esteem, 35(72.9\%) of them had moderately adequate self-esteem and none of them had adequate self-esteem. In control group 13(28.9\%) of the adolescents had inadequate self-esteem, 32(71.1\%) of them has moderately adequate self-esteem and none of them had adequate self-esteem (Tables 1 \& 2).
Analysis revealed that in post-test, in the study group $36(75.0 \%)$ of the adolescents had adequate self-esteem, 12(25.0\%) of them had moderately adequate self-esteem and none of them had inadequate self-esteem. In control group 13(28.9\%) of the adolescents had inadequate self-esteem, 32(71.1\%) of them has moderately adequate self-esteem and none of them had adequate self-esteem (Table 3).

Table 3: Frequency and percentage distribution of post-test level of self esteem among adolescents in study and in control group $\mathrm{n}=93$.

\begin{tabular}{|c|c|c|c|c|}
\hline \multirow{2}{*}{ Level of self-esteem } & \multicolumn{2}{|c|}{ Study group (n2=48) } & \multicolumn{2}{c|}{ Control group (n1=45) } \\
\cline { 2 - 5 } & $\mathbf{f}$ & $\mathbf{0}$ & $\mathbf{f}$ & 28.9 \\
\hline Inadequate self esteem & 0 & 0 & 32 & 71.1 \\
\hline Moderately adequate self-esteem & 12 & 25 & 0 & 0 \\
\hline Adequate self-esteem & 36 & 75 & 32 & 0 \\
\hline
\end{tabular}

Analysis revealed that with respect to study group, mean value of pre-test is 12.73 with standard deviation 4.365; mean score of post-test is 22.71 with standard deviation 5.683 and in control group the pre-test mean value is 14.33 with standard deviation 4.904 and post-test mean is 14.22 with standard deviation 4.838

computed by paired t-test, the t-value is 14.377 and $p<0.01$ which suggests that there is a statistical significant difference between pre and post self-enhancement programme on self-esteem. Hence it concludes that Self enhancement programme provided is very effective in improving self-esteem of orphan adolescents (Table 4).

Table 4: Effectiveness of self-enhancement program on self-esteem among adolescents in study group.

\begin{tabular}{|c|c|c|c|c|c|c|}
\hline Test & \multicolumn{2}{|c|}{ Pre-test score } & \multicolumn{2}{c|}{ Post-test score } & \multicolumn{2}{c|}{ Paired t-test } \\
\hline & Mean & SD & Mean & SD & t - value & \multirow{2}{*}{$14.377 \mathrm{df}=44 \quad \mathrm{P}$ P $<0.01 * *$} \\
\hline Study group & 12.73 & 4.365 & 22.71 & 5.683 & 4.838 & \\
\hline Control group & 14.33 & 4.904 & 14.22 & & \\
\hline
\end{tabular}

\section{Discussion}

In this study the pre-test level of self-esteem among adolescents reveals than none of them had adequate self-esteem, 35(72.9\%) of them had moderately adequate self-esteem and $13(27.1 \%)$ of them had inadequate self-esteem in the study group and in the control group none of them had adequate self-esteem, 32(71.1\%) of them had moderately adequate self-esteem and 13(28.9\%) of them had inadequate self-esteem. Analysis of the post-test level of self- 
esteem among adolescents shows the drastic improvement that $36(75 \%)$ of them had adequate self-esteem, 12(25\%) of them had moderately adequate self-esteem and none of them had inadequate self-esteem in study group and in the control group none of them had adequate self-esteem, $34(75.6 \%)$ of them had moderately adequate self-esteem and 11 (24.4\%) of them had inadequate selfesteem. this finding supported with Anubha Dhal et al. [8] to assess the self-esteem, loneliness and attachment styles among orphan adolescents and examine their association with each other and with age and gender in a sample of 110 adolescents from an orphan school in Delhi. It reported that orphan adolescents studying in an orphan school reported moderate levels of self-esteem, high level of loneliness and a moderate secure attachment style [8,9].

The effectiveness of self enhancement programme on selfesteem among adolescents revealed that with respect to study group the mean value of pre-test was 12.73 with standard deviation of 4.365 , mean score of post-test was 22.71 with standard deviation of 5.683 whereas ' $t$ ' value is 12.820 and $p<0.000$ which shows a statistically significant difference between mean and standard deviation of pre-test and post-test at $\mathrm{p}<0.01$ level. As far as control group is concerned the mean value of pre-test was 14.33 with standard deviation of 4.904, mean score of post-test was 14.22 with standard deviation of 4.838 whereas the ' $t$ ' value is 0.759 and $p$ value is 0.452 . The result of the present study is consistent with the findings of the study conducted by Jayne E.Stake et al. [10] conducted a study to assess the effects of self enhancement programme on the performance self-esteem of orphan adolescent boys and girls. A three month follow-up for the 103 subjects available at follow-up; low self-esteem subjects showed greater increases than high self-esteem subjects. Changes in self-esteem were related to the student's perception of teacher's reaction to their assertive behavior [10].

\section{Conclusion}

Self enhancement programme is one of the most effective therapeutic interventions found to be very effective in improving the self-esteem among adolescents residing at orphanages. This interventional study was done to assess the effectiveness of self enhancement programme on self-esteem among adolescents residing at selected orphanage homes in Kancheepuram District. The findings were consistent with the literature and it was concluded that self enhancement programme was effective in improving the self-esteem of orphan adolescents. This study recommends that periodically conduct such program in orphan homes/school for the mental wellbeing of the adolescent.

\section{References}

1. Townsend Mary C (2010) Psychiatric Mental Health Nursing- Concepts of care in evidence based practice ( $6^{\text {th }}$ edn.), Jaypee Brothers, New Delhi, India.

2. World health report.

3. National report on the state of self-esteem (2013)

4. Data Spotlight Report from the Substance Abuse and Mental Health Services Administration (SAMHSA).

5. DuBois DL, Burk-Braxton C, Swenson LP, Tevendale HD, Lockerd EM, et al. (2002) Getting by with a little help from self and others. Self-esteem and social support as resources during early adolescence. Developmental Psychology 38(5): 822-839.

6. Patel V, Chinthanie Ramasundarahettige, Lakshmi Vijayakumar, MD, JS Thakur, Vendhan Gajalakshmi, et al. (2012) Suicidal morality in India. The Lancet 379 (53): 2343- 2351.

7. Firdevs, Zeynep (2012) The Self-Esteem, Perceived Social Support and Hopelessness in Adolescents: The Structural Equation Modeling. Educational Sciences Theory \& Practice 12(4): 2406-2412.

8. Hirsch B, DuBois D (2011) Self-esteem in early adolescence: The identification and prediction of contrasting longitudinal trajectories. Journal of Youth and Adolescence 20(1): 53-72.

9. Anubha Dhal, Sangeetha Bhatia, Vidhi Sharma, Priyanka Gupta (2006) Adolescents self-esteem, attachment and loneliness, Journal of Indian Association for child and adolescence mental health 3(2): 61-63.

10. Jayne E Stake (2014) The Effects of self-enhancement programme on the performance self-esteem of adolescent girls. Journal of Youth and Adolescence 12(9): 435-438.

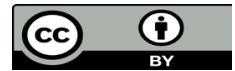

This work is licensed under Creative Commons Attribution 4.0 License

To Submit Your Article Click Here: Submit Article

DOI: $10.32474 /$ LOJNHC.2018.01.000114

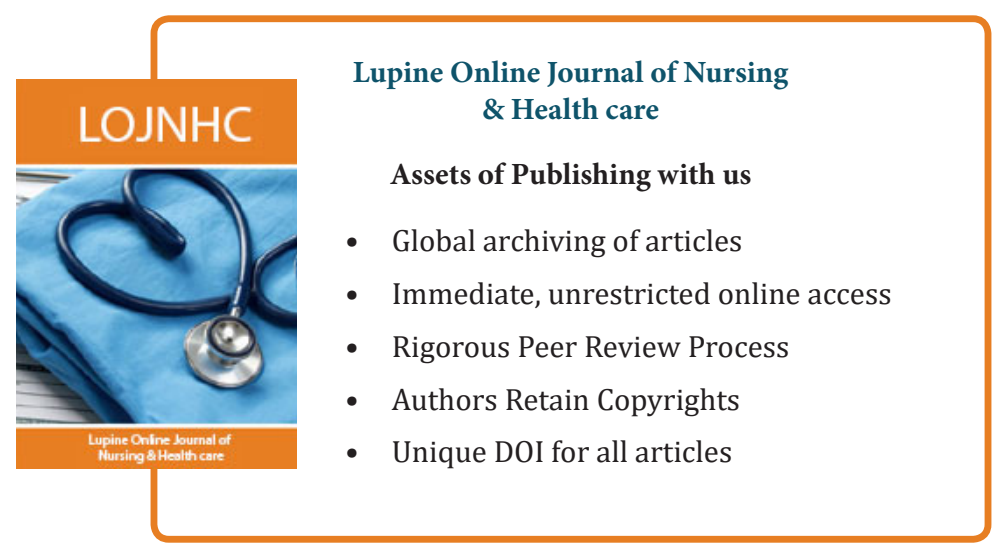

